\title{
CARA Y CUERPO DEL HORROR: REPRESENTACIONES DE INGRID OLDEROCK
}

The Face and Body of Horror: Representations of Ingrid Olderock

\author{
BERNARDITA LLANOS \\ BROOKLYN COLLEGE (EEUU) \\ Bllanos@brooklyn.cuny.edu //orcid.org/0000-0001-5835-5144
}

RECIBIDO: 8 DE JULIO DE 2019

ACEPTADO: 10 DE MAYO DE 2020

RESUMEN: En el imaginario chileno Ingrid Olderock se construye como un monstruo ligado al poder dentro de la institución de Carabineros y luego a los organismos de la represión de la dictadura de Pinochet. Olderock representa un extremo emblemático donde se imbrican distintos discursos sobre la violencia y la locura y que la figura de la camiona condensa en tanto personaje abyecto. Lo horroroso no vincula solo con la mujer sino con la sexualidad no normativa de la despiadada torturadora.

Olderock aparece en la obra teatral La mujer de los perros (2017) de Eduardo Vega donde la locura, la falta de feminidad, y el deseo de dominar y hacer sufrir son su marca. El cuerpo femenino abyecto se asocia significativamente a su brutalidad despiadada y a la ausencia de justicia. Por otra parte, en la obra de teatro de Irán 3730 (2019) de Patricia Artés, Olderock no aparece en escena a pesar de ser la encargada principal de la casa de tortura La Venda Sexy en cuyo inmueble se desarrolla la acción dramática del presente. Estas dos miradas frente al pasado y de Olderock se sustentan en visiones distintas sobre el legado dictatorial. La de Artés tiene una perspectiva de género que permite una mayor comprensión de la historia y el rol de las mujeres militantes en el pasado. Su impacto en el presente, desplaza a la torturadora, y realza el activismo feminista y la lucha política de las ex militantes por el reconocimiento y la justicia.

PALABRAS ClAVE: Tortura sexual, La Venda Sexy, entrenadora de perros, DINA, género y Derechos Humanos

ABSTRACT: In the Chilean imaginary Ingrid Olderock is constructed as a monster associated with the power of the institution of Carabineros and later with the agencies of repression in the Pinochet dictatorship. Olderock represents an emblematic extreme where different discourses on violence and insanity overlap and that the butch figure condenses as an abject character. Horror is linked not only to gender but to the non-normative sexuality of the cruel torturer.

Olderock appears in the play La mujer de los perros (2017) by Eduardo Vega which underscores her insanity, lack of femininity, and a desire to dominate and inflict pain are her signature. The abject female body is here significantly associated with a heartless brutality and the absence of justice. On the other hand, the play Irán 3730 (2019) by Patricia Artés, Olderock is not seen even though she was in charge of the torture house La Venda Sexy in the property where the dramatic action unfolds in the present. These two takes towards the past and Olderock sustain themselves in different visions of the legacy of the dictatorship. Artés has a gender perspective that allows for a broader understanding of history and the role of women activists in the past. Their impact in the present displaces the torturer and highlights feminist activism and the political struggle of former militants for their recognition and for justice.

KEYWORDS: Sexual torture, La Venda Sexy, dog trainer, DINA, gender and Human Rights

Llanos, Bernardita.

"Cara y cuerpo del horror: representaciones de Ingrid Olderock"

Kamchatka. Revista de análisis cultural 16 (Diciembre 2020): 431-445.

ISSN: 2340-1869 DOI: https://doi.org/10.7203/KAM.16.15579 
Los episodios más violentos de la historia dictatorial reciente de Chile han recibido atención en diversas manifestaciones culturales que recorren libros, crónicas, obras de teatro, novelas y testimonios. Entre ellas los llamados géneros realistas se han abocado a la tarea de representar no solo a las víctimas sino más recientemente a los perpetradores de violaciones de los derechos humanos, algunos de los cuales evadieron la justicia y nunca fueron juzgados. Dentro de estas representaciones el poder judicial como organismo independiente cuyo rol es velar por la justicia y proteger los derechos de la ciudadanía aparece como una de las estructuras más débiles y problemáticas del estado que en muchos casos protegió a los perpetradores en vez de las víctimas.

En el siguiente artículo se propone un análisis de las representaciones de Ingrid Olderock, conocida torturadora y agente de los servicios clandestinos de la dictadura, considerando los aportes críticos al estudio de los y las cómplices de la dictadura en Chile realizados por Michael Lazzara, Leigh Payne y la escritora Diamela Eltit. Por otro lado, el periodismo investigativo de Alejandra Matus y Nancy Guzmán sobre Ingrid Olderock ha sido fundamental para sentar las bases históricas de la biografía de la ex torturadora y su impacto dentro los servicios secretos.

Algunas de las preguntas que guían este artículo son: ¿qué relación hay entre la violencia y una mujer masculina como Olderock? ¿De qué manera las representaciones simbólicas como el teatro y la crónica contribuyen o cuestionan la idea de que la mujer masculina sea inherentemente violenta? ¿Puede una perspectiva feminista alterar este tipo de representación de género? Si lo hace ¿cómo lo logra y qué efectos tiene? A través del análisis de dos obras de teatro recientes y crónicas de las últimas dos décadas, la performance de género de Olderock se ve ligada a la violencia más brutal superponiendo su trabajo en los centros de detención y tortura con su cuerpo deforme, desaseado y lésbico. Además, se le atribuyen rasgos masculinos secundarios como la voz ronca y un ahombramiento en todos sus gestos y modos en general. Por otra parte, estas cualidades identitarias parecen vincularse íntimamente al desequilibrio mental que se le atribuye y al terror que infundía en otros, convirtiéndola en una de las figuras femeninas más abyectas de la dictadura.

En el imaginario chileno la figura de Olderock se construye como un monstruo ligada al poder dentro de la institución de Carabineros y luego a los organismos de la represión: la DINA (Dirección de Inteligencia Nacional) y la CNI (Central Nacional de Informaciones) de la dictadura de Augusto Pinochet. La afición por los perros -tanto para adiestrarlos como para torturar- que singulariza a Ingrid Olderock se representa en la obra teatral La mujer de los perros (2017) de Eduardo Vega que enfatiza su falta de feminidad y goce por dominar y hacer sufrir. La violencia de este cuerpo femenino abyecto, por otro lado, se asocia significativamente a su brutalidad despiadada y, por otro, al escape de la sanción judicial, es decir a la impunidad. Más aún, podría decirse que su representación como lesbiana con sobrepeso la animaliza como denotan los despectivos apelativos con que la nombran otros agentes; "la perra," "la chancha" (cerda). El lugar de la abyección que ocupa Olderock pareciera apuntar a que la masculinización como rasgo central de una camiona (lesbiana en Chile) y de la mujer que se viste como hombre, conlleva formas de violencia aberrantes. El poder que ocupó la excapitán de Carabineros por ser protegida del general Manuel Contreras, fundador y director de la DINA, quedaría en un segundo plano a pesar de ser realmente el aspecto determinante en las acciones de 
la torturadora. La lesbiofobia estructura también el discurso de la abyección femenina, en este caso de manera pedagógica para representar a Olderock aliando terror y condena hacia quien se acusa de violar a prisioneros y prisioneras con un perro. Su poder destructivo, del que hay testimonios y casos judiciales pendientes, es evidente, pero aquí quisiera explorar el nudo entre cuerpo y sexualidad femenina que circula en la mayor parte de los discursos en torno a la torturadora en los que su criminalidad es parte integral de su lesbianismo y su deformidad (física y moral).

La obra de teatro Irán 3730 de Patricia Artés es, a mi modo de ver, la primera que logra modificar esta representación hegemónica patriarcal sobre la violación de los DDHH y la torturadora al sacar a Olderock de escena y nunca mostrarla. La ausencia de su cuerpo permite centrarse solo en sus acciones como agente de la DINA. Al substituir la figura de la torturadora por la casa de tortura la Venda Sexy que Olderock dirigió, se logra una nueva mirada al pasado que revela el sistema de represión y su funcionamiento junto a las estructuras de género. En el sistema dictatorial hay toda clase de abusos y diversos niveles de colaboradores y cómplices de la dictadura como señala el libro Civil Obedience. Complicity and Complacency in Chile since Pinochet (2018) de Michael Lazzara. Dentro de este espectro, Olderock representa un extremo emblemático donde se imbrican distintos discursos sobre la violencia y la locura y que la figura de la camiona condensa en tanto personaje abyecto. En este sentido, el imaginario chileno vincula lo horroroso no solo con la mujer sino con una sexualidad no normativa. En este caso concreto los crímenes de los que se la acusa fueron muestras de su pacto con el poder patriarcal y asesino de la dictadura que la reconoció y protegió. Su afición por el castigo corporal brutal era parte del disciplinamiento que aprendió en el hogar familiar, directamente de su madre, quien la golpeaba siendo niña y adolescente cada vez que no cumplía sus órdenes. Carabineros y las agencias represivas profesionalizaron esta pedagogía de la sumisión y el dominio brutal lo que la pieza de Vega pone de manifiesto.

Olderock perteneció a la primera generación de mujeres en integrarse en los sesenta a Carabineros, la Policía Nacional chilena, contra el deseo de su padre que quería que fuera una mujer tradicional en el hogar. Olderock además fue la primera mujer paracaidista en el país, mostrando grandes habilidades atléticas que en la época estaban fuera del alcance de las mujeres. Era también experta en equitación, tenía cinturón azul en judo y practicaba tenis y montañismo y era una gran entrenadora de perros, según narra Nancy Guzmán. Todas estas habilidades y actividades deportivas se consideraban propias de los hombres dejándolas fuera de los parámetros de la feminidad y sus expectativas sociales.

El género en su performatividad, tal como lo ha abordado Judith Butler, produce efectos que se consolidan en la manera de hablar, conversar, moverse, o gesticular, produciendo lo que entendemos como una mujer o un hombre. En este sentido, el género se produce y reproduce a través de su performatividad todo el tiempo alojando la paradoja de la agencia y la represión de la sujeto. Al teorizar el género, Butler lo desprende del sexo y del sistema binario, haciéndolo una entidad libre que puede fácilmente significar como masculino y varón a un cuerpo-hembra (1990: $6)$. 
El género y la sexualidad serán precisamente fuentes de diferencia en Olderock que impactan su éxito y fracaso dentro de la institución militar. A pesar de todo su poder, es depreciada y evitada por sus pares. Así, el camaleonismo de género y su movilidad se parecen al de las colaboradoras Luz Arce y Marcia Alejandra Merino tal como la escritora Diamela Eltit las interpreta en términos de las maniobras, transgresiones y travestismos que realizan para avanzar en organizaciones rígidas y patriarcales donde la violencia es un componente esencial. Sus cambios ideológicos y desplazamientos al interior de estructuras masculinas y jerárquicas en la izquierda y luego en las agencias de la represión, revelan las diversas performances de género a las que recurren. Para ser reconocidas, de hecho, se transforman en hombres según el ideal militar, negando todo lo que las vulnera o debilita, en especial el cuerpo femenino (2000: 66-68). La debilidad en este contexto se identifica con la mujer (de su casa, esposa y madre) mientras quienes son soldados, militantes y agentes se proyectan como duras, disciplinadas y fuertes, aunque en el caso de Arce y Merino fueran irremediablemente quebradas por la tortura. La obra Medusa (2010) de Ximena Carrera tiene como personajes centrales a tres torturadoras, antiguas militantes de izquierda convertidas a la ideología dictatorial a través de la tortura y el terror al que son sometidas dentro de los centros clandestinos y fuera de ellos. En la obra las tres mujeres comparten un departamento mientras son supervisadas por la DINA, organismo para el que trabajan en diversas tareas. Las similitudes en las formas de educar o "reeducar" a las mujeres para convertirlas en leales agentes paramilitares son muy semejantes a las que despliega Olderock en la obra La mujer de los perros ${ }^{1}$, donde los signos de la feminidad se sustituyen por los de la masculinidad.

\section{REPRESENTACIONES DE OLDEROCK}

La obra de teatro La mujer de los perros es parte de la Trilogía del Horror donde el director y dramaturgo Eduardo Vega revisa el pasado violento reciente y la memoria a través de la dramatización de personajes icónicos de la dictadura. En La mujer de los perros se centra en la biografía de Olderock y toma el libro de Nancy Guzmán Ingrid Olderock. La mujer de los perros como su referencia principal. Ingrid Olderock es la protagonista y aparece en escena recluida en el Hospital de Carabineros, aunque no se sabe bien la razón ya que parece haber tenido un accidente (lleva una venda que le rodea la cabeza) y se queja de dolor y también muestra una gran inestabilidad psíquica con brotes paranoicos. Se presenta en escena vestida con uniforme kaki de campaña, gruesa y con gestos y maneras masculinas y autoritarias. El contraste en las performances de género entre Olderok y las dos enfermeras que la atienden se acentúa por la feminidad y vestuario de éstas (a la usanza de los años cuarenta, pero con faldas largas que semejan monjas trabajando para las FFAA). La excapitán les grita e insulta como si fueran sus alumnas y les dice que deben simular "feminidad", pero ser ante todo "duras." De este modo, Olderock revive en ellas parte de las enseñanzas que les dio a las 70 mujeres que formó en la

\footnotetext{
${ }^{1}$ Las tres torturadoras que protagonizan Medusa dramatizan las biografías de las históricas colaboradoras Marcia Alejandra Merino, Luz Arce y Maria Alicia Uribe, quienes vivieron dominadas por "el miedo corrosivo e inmenso a la muerte" que la DINA ejercía sobre ellas. Para más información consultar el artículo "Las imperdonables" de Alejandra Matus.
} 
Escuela femenina Las Rocas de Santo Domingo, la primera brigada de agentes de seguridad y torturadoras.

La pieza La mujer de los perros dedica una serie de escenas que dramatizan la enseñanza teórico-práctica y los objetivos que guiaban a Olderock al convertir a muchachas de las clases populares, muchas provenientes del campo, en agentes de los servicios secretos de la dictadura. Olderock convencía a los padres del futuro profesional y social que esperaba a sus hijas en Carabineros bajo su tutela. De hecho, Olderock seleccionó y entrenó a las futuras agentes paramilitares; ella se encargaba de elegirlas y enseñarles a rendir y "hacer bien sus tareas" en lo que fue una suerte de escuela femenina de la institución para torturadoras. A estas jóvenes Olderock les enseñaba las técnicas usadas en la guerra contrainsurgente y las diversas tareas represivas que luego practicarían.

Los objetivos principales de la escuela eran el "buen rendimiento" y la "obediencia ciega a sus superiores" (Guzmán, 2014: 105). Según Olderock en Santo Domingo se les enseñaba "de todo," desde "el uso de armas, contrainteligencia, seguimientos, choferes, trabajo operativo interrogatorio, enfermería, modales." Después del curso las alumnas se "fueron a cumplir tareas operativas y la aplicación de torturas de detenidos." Gladys Calderón, por ejemplo, además de aplicar Pentotal y otras sustancias letales, participó en los lanzamientos de cadáveres al mar según cuenta su maestra (Guzmán, 2014: 57). Parte de esta historia a cargo del centro de instrucción femenino aparece en la obra de teatro La mujer de los perros donde se entrecruzan el disciplinamiento militar y el deseo de Olderock por las jóvenes.

Para la capitana de Carabineros, el rol de las mujeres era clave en la construcción de una nueva sociedad bajo una misión y visión militarista de la nación. Siendo gran admiradora de los nazis y de su teoría de la superioridad aria, Olderock pensaba que los militares chilenos debían someterse a un orden y disciplina férreos con el fin de destruir a los enemigos de la patria, pero consideraba que los agentes de la DINA no lo hacían bien porque "No había gente preparada para interrogar, así que hacían las cosas a lo bruto" (Guzmán, 2014: 111). En su papel de torturadora y entrenadora de mujeres, su trabajo y prácticas se implementaron con total impunidad y conocimiento de sus superiores. Era integrante de la Brigada Purén, uno de los diversos grupos en que se dividía la estructura piramidal de la DINA, junto a otras torturadoras crueles como la subteniente de Carabineros, Palmira Isabel Almuna Guzmán, alias "la Pepa," quien fue torturadora en la casa José Domingo Cañas bajo las órdenes de Ciro Torré Saéz. La Pepa trabajó, posteriormente, bajo las órdenes del brigadier Pedro Espinoza Bravo, el segundo después de Manuel Contreras en la DINA. Como Olderock, Almuna era encargada de seleccionar e instruir a futuras agentes, pero en su caso el objetivo era que ellas se infiltrasen "como mujeres frívolas y bonitas en diversos ámbitos de relevancia política nacional".

En la Escuela Femenina una de las alumnas de Olderock fue Rosa Humilde Ramos, alias "la comandante", a quien reclutó cuando tenía 20 años y que se convirtió en torturadora en la casa José Domingo Cañas y Villa Grimaldi y fue integrante de la Agrupación Águila de la Brigada Caupolicán. Su recuerdo "es imborrable entre los sobrevivientes por su apariencia masculina y el sadismo de sus torturas". Rosa Humilde -quien de humilde no tenía nada según Olderockcomparte con su antigua profesora el rechazo a la feminidad tradicional y a la apariencia femenina 
y adopta vestimentas, corte de pelo y actitudes identificadas como masculinas tal como Olderock. Esta performance de género y la masculinización de las dos torturadoras, se realiza en un entorno donde los hombres se creían "supermachos" y "macanudos" por ser "hombres con armas," de acuerdo con la propia Olderock (Guzmán, 2014: 106, 2014: 60). Este comentario pone de manifiesto que las mujeres eran consideradas subordinadas y vistas como inferiores a sus pares masculinos. La manera en que estas dos mujeres compensaron esta desigualdad de género fue precisamente masculinizándose y actuando de forma aún más violenta que los varones. Más aún, ambas se convirtieron en poderosas y temidas funcionarias dentro de la DINA, organismo que según su director Manuel Contreras, necesitaba "ladrones, prostitutas y asesinos" (Guzmán, 2014: 93). De este modo, las mujeres entraban a la agencia para todo servicio y de libre acceso para los funcionarios. Olderock critica a Rosa Humilde precisamente por haber tenido relaciones sexuales y tal vez un hijo con el coronel Ricardo Lawrence. La califica como "una rajá" en la jerga coloquial (una persona sin límites) que se volvió "mala” y "peligrosa". Además, la propia Olderock aparentemente, le tenía miedo después de que le contara que había seguido y matado a un hombre con sus propias manos (Guzmán, 2014: 106). Lo que no menciona Olderock es que muchas de estas "mujeres malas" como las denomina, se habían prostituido por ella y Contreras. La ex agente Sonia del Carmen Valenzuela recuerda que en los departamentos de calle Paraguay donde vivían, había cámaras de filmación y máquinas fotográficas escondidas con el propósito de recabar información comprometedora de las personalidades públicas que ellas llevaban ahí (militares y políticos conservadores y pro Pinochet). Olderock estaba a cargo de estas mujeres y supervisaba lo que hacían (Guzmán, 2014: 106-107). La obra de teatro La mujer de los perros también muestra, aunque sin tanto detalle, el poder y la influencia que Olderock tenía sobre sus alumnas. Por otro lado, la obra Medusa dramatiza lo que estos departamentos eran, una suerte de recintos vigilados por cámaras y micrófonos escondidos que grababan todo lo que pasaba allí y lo que debían hacer las agentes.

En la obra de Vega, la violencia irrumpe en los gritos de dolor y los insultos de Olderock en el hospital y en los flashbacks que aparecen teñidos por los delirios de grandeza y el terror a ser asesinada por la propia institución de Carabineros. En la pieza el trauma del atentado que sufrió Olderock en 1981 y su trabajo como agente represiva estallan en las crisis sicóticas donde confunde pasado y presente, negando haber torturado y asesinado a las detenidas y prisioneros políticos a su cargo. Dentro de su locura según el discurso dramático, Olderock se percibe como una fiel servidora de la DINA sin haber cometido ningún crimen ni violación de los DDHH, lo que evidentemente es una distorsión de la verdad. Las acciones represivas de Olderock saltaron a la luz pública por primera vez en el programa de la TV 60 minutos después del atentado que sufrió en 1981 por la célula mirista Lumi Videla, la cual quería hacer justicia por la muerte de la militante detenida desaparecida del mismo nombre, en cuya muerte Olderock parece haber estado directamente implicada ${ }^{2}$.

Alejandra Matus en su semblanza de Olderock, incluye el testimonio de una vecina que conocía a la familia por años y quien recuerda que: "La Ingrid llegaba con su traje de oficial de

\footnotetext{
2 Se presume que Lumi Videla fue asfixiada durante una violación mientras estaba detenida por la DINA después de lo cual su cuerpo habría sido arrojado a la embajada de Italia.
} 
Carabineros. Aparentemente se sentía muy orgullosa de él. Era algo arrogante y amachada. Tenía una voz ronca muy potente" (Matus, 2015: 142). En esta descripción se expresa la performance de género de Olderock y su admiración por el poder militar. Su manera de estar en lo público aparece muy distante del estereotipo femenino chileno del ángel del hogar y del modelo de la dictadura. Por el contrario, Olderock era percibida como "amachada," con características como el orgullo, la arrogancia y una voz fuerte y ronca, atributos típicamente asociados a los hombres que unidos a un uniforme se corresponden con el poder militar en dictadura. El fetiche del uniforme y el dominio del otro, son dos leit motivs que también aparecen en la obra de teatro y otras representaciones de Olderock.

El libro Ingrid Olderock. La mujer de los perros de la periodista e historiadora Nancy Guzmán, que como hemos mencionado arriba es la fuente en la que se basa la representación teatral de Vega, presenta una acuciosa investigación acompañada de entrevistas que Olderock le concedió a la autora. Guzmán reúne también entrevistas con sobrevivientes del centro de detención clandestino la Venda Sexy, quienes fueron torturados y torturadas por Olderock, lo que ella nunca reconoció. Olderock siempre "siguió manifestando orgullo" por haber pertenecido a la DINA, grupo que "definía como los 'Salvadores de la patria”' (Guzmán, 2014: 151-152). Su admiración y lealtad a Manuel Contreras y a Augusto Pinochet se mantuvieron intactas.

Olderock está muy cerca del célebre y temido torturador de la DINA, Osvaldo Romo, cuyo retrato sensacionalista como sádico agente se dio a conocer fuera de Chile primero en una entrevista que dio en los 90s a la cadena americana Univisión precisamente a través de las gestiones de Nancy Guzmán. Como subraya Leigh Payne el programa presentó a Romo como un sicópata, un asesino irredento, un torturador y violador que debía pasar el resto de su vida encarcelado (Payne, 2008: 118). Romo fue el primer perpetrador chileno en presentarse públicamente y hacer una confesión en un programa de la TV sobre los asesinatos, torturas y desapariciones de detenidos. A pesar de negar la tortura y en especial el abuso sexual que cometió, todo el relato de Romo sugiere que sus acciones (tirones, agarrones, golpes) fueron malinterpretadas por las prisioneras como violaciones sexuales, revelando la fabricación de su historia sobre la que pesan 80 acusaciones (Payne, 2008: 114-115 y 124). De igual modo, Olderock fabrica e inventa y sobretodo niega tener responsabilidad alguna. Sin embargo, su versión hace aguas, tal como la de Romo, al confrontarla con los testimonios reales y los que aparecen en las obras de teatro en especial en la obra de Patricia Artés, quien los incluye a través de la voz auténtica de las sobrevivientes.

\section{GENEALOGÍA DEL TORTURADOR/A}

La normalidad e impunidad en la que verdugos como Olderock vivieron queda explicitada en el texto "A la vuelta de la esquina" que Claudia Donoso y Paz Errázuriz escribieron unos días después de la muerte natural de Olderock en Alemania en 2001. Las autoras la vieron y reconocieron por casualidad mientras compraba pan en una tienda del barrio de Nuñoa donde vivían ambas al igual que Olderock, vecina que andaba "impunemente a la vuelta de la esquina" como afirman. Su imagen fue la primera imagen televisiva de una torturadora y sus fotografías aparecieron en todos los diarios después de haber sufrido el atentado en 1981. Olderock era "una 
representante de la abyección," una "ogresa," a quien Donoso y Errázuriz entrevistarían en su "cueva" a pesar y en contra de sus propias cavilaciones y fantasías siniestras sobre la terrible torturadora de la DINA (2001: 14). Sin embargo, a pesar del miedo y aquí radica a mi juicio el aporte de esta crónica sobre Olderock, vieron a una mujer "desaliñada, con cutis rojizo, con sobrepeso, y una patética ausencia de expresión en el rostro" que en nada semejaba un monstruo (2001: 14). Durante la entrevista que finalmente deciden hacerle, la necesidad de distinción e importancia delirante de Olderock saltan a la luz cuando afirma que se siente orgullosa de tener una bala en el cerebro producto del atentado. Esto según ella era prueba de que no era una más (2001: 15). En otro segmento, Olderock afirma que obedecía y realizaba las funciones que le mandaban y que siempre "cumplía las órdenes." De acuerdo a sus valores y creencias marciales cuando un jefe da una orden, el subalterno "está para cumplirla" (2001: 17). La "doctrina de la nueva fe" como denomina Guzmán al credo de Contreras consistía en "obediencia ciega y la disciplina basada en el terror (2001: 52). De modo similar a Osvaldo Romo, quien obedecía "ciegamente a sus jefes", la obediencia incondicional a los superiores, sin resistencia ni duda, es un rasgo que se repite entre los agentes de este organismo represor (Guzmán, 2000: 41). Por otra parte, si la necesidad de reconocimiento se expresa en complacer y obedecer a los superiores, no es así con quienes son sus subordinados o considerados débiles, ya que a quienes ven como inferiores, los maltratan con suma violencia y se ensañan causándoles dolor y humillaciones de toda índole. El abuso sexual degradante se da específicamente como una forma de tortura con las prisioneras por su género. La risa y la exaltación que su propia descripción de las diversas torturas le provoca a Romo, muestra el sadismo y los delirios de grandeza que padece (Guzmán, 2000: 166-167).

La tortura según los manuales de la CIA se usa para infundir debilidad, pavor, culpa y dependencia con el fin de conseguir la regresión del y la detenida, por un lado, y la ambivalencia emocional que el odio y dependencia del interrogador/torturador producen (Guzmán, 2000: 115). Romo era experto en cada uno de los métodos y describe con lujo de detalles las transformaciones fisiológicas que el dolor causa en el cuerpo. Su experiencia se revela en el lenguaje y las imágenes denigrantes que usa para describir a las mujeres torturadas con el pau arara, quienes aparecen como "corderos" que "quedan con todo abierto" (Guzmán, 2000: 166). Las cargas de electricidad se colocaban en las partes más sensibles del cuerpo y los órganos genitales calculando el tiempo y deseo de los torturadores mientras los presos y presas "se contorsionaban como locos," según Romo.

Como Olderock, Romo, uno de los más sanguinarios torturadores, en sus relatos del pasado también se vanagloria de la información que posee y la administra, edita y distorsiona a voluntad. Cada episodio, personaje y acción que cuenta aparece de tal modo que su protagonismo y personalidad se realzan en medio de la atrocidad de los crímenes cometidos. Guzmán en este libro tal como la crónica de Paz Errázuriz y Claudia Donoso, reitera que estos son "nuestros vecinos, se sientan a la mesa de al lado en el restaurante," develando no solo su vida normal sino el hecho que "caminan por las calles con la cabeza en alto" (2000: 16-17), impunes.

Ambos perpetradores se sentían orgullosos del poder que les daban las armas y la autoridad en la DINA, rasgo que aparece tanto en las entrevistas, crónicas y obras de teatro. En la Escuela de Carabineros Olderock había aprendido la jerarquía y la importancia de la subordinación para 
ejercer el poder. Su lugar de analista de documentos religiosos en el centro clandestino Villa Grimaldi, luego como persona de confianza de Manuel Contreras para fundar la Escuela Femenina de la DINA y, finalmente, su poder incuestionable en Tres Alamos y La Venda Sexy, revelan su alto rango en la estructura militarizada de la DINA y en la policía nacional (Guzmán, 2014: 17). Más aún poseía una autopercepción distorsionada de sí como persona de bien, sobre todo cuando narra cómo era antes del atentado. En ese pasado anterior a 1981 se representa como una persona refinada en el lenguaje, cristiana y "muy correcta. Correcta, correcta, correcta" (Guzmán, 2000: 18). Todo en ella era un conjunto de virtudes cristianas y militares. El contraste con el presente y su deterioro físico y psíquico, producto de la bala en el cerebro según ella misma, se muestra en que dice "garabatos," es "al lote" y ya le da lo mismo tener su casa impecable. La ausencia de autodisciplina se ve en que ya no se levanta a las 5:00 o 6:00 am como antes. Según Olderock todo esto ocurre porque no tiene ánimo y "el espíritu de trabajo y el entusiasmo se le borró", al igual que tocar el violín (2014: 18). Esta nueva arista en su autorrepresentación nos la muestra derrotada y temerosa, alentada solo por el deseo de abandonar Chile.

En las entrevistas Olderock afirma haber perdido parte de su memoria y que tiene lagunas por eso durante un tiempo solo hablaba alemán ya que el español se le había olvidado por completo después del atentado. Lo que se mantiene igual, sin embargo, es su convencimiento de que no ha hecho nada ilegal o incorrecto por lo que no tiene porqué pedir perdón. Olderock tenía pleno conocimiento de los crímenes de tortura y violaciones de DDHH que se cometían bajo la dirección de Manuel Contreras, y lo que le preocupaba era no ser inculpada por el sistema judicial y por el organismo clandestino, la Dinita que estaba compuesto por el círculo de ex agentes que seguía bajo las órdenes de Contreras "aún aunque estuviera encarcelado en Punta Peuco," prisión de alta seguridad para los altos rangos de la dictadura donde estuvo cumpliendo sentencia hasta su muerte en 2015 (Matus, 2014: 156). Olderock debía informar a la dinita de las declaraciones que hacía a los tribunales y de lo que le preguntaban (Matus, 2014: 156).

En la obra de teatro La mujer de los perros, se reitera la falta de moral y la crueldad en las sesiones de tortura sexual con el perro Volodia que aparecen en los recuerdos repentinos y fragmentados de Olderock, quien es una figura delirante presa del miedo a ser asesinada y sus propios intentos de suicidio.

En la obra teatral Irán 3730 de Patricia Artés nos encontramos con un acercamiento nuevo y distinto a la temida torturadora. Lo que salta a la vista en esta obra es la mirada feminista en la dramatización de la tortura entendida como un crimen de lesa humanidad y de carácter políticosexual que sufrieron las presas políticas de la dictadura y que sigue afectando a las mujeres en la actualidad. La revisión del pasado se da en que la Venda Sexy, antiguo centro de torturas sexuales liderado por Olderock como se señaló anteriormente, es el domicilio de una familia de clase media en el presente que no se interesa por todo lo ocurrido ahí. Así, se pone el acento en la casa de tortura que dirigía Olderock y que en el presente dramático es la residencia de un matrimonio que niega el pasado y que a pesar suyo deberá confrontarlo. A través de Valentina, la joven adolescente, hija de los dueños de la casa, los espectadores van descubriendo la historia oculta y aberrante del recinto. Aquí se menciona a Olderock y sus atrocidades a través de los testimonios de las sobrevivientes en vOz en off, gesto político que les devuelve la palabra. Olderock es 
desmitificada como la encarnación de la monstruosidad y presentada como una agente del estado, otro eslabón dentro de la máquina de muerte. Las voces de las sobrevivientes identifican y acusan a Olderock a través de la investigación histórica que el trabajo escolar de Valentina le va revelando, pero Olderock no aparece ni entra en la escena. Irán 3730 incorpora las palabras, las experiencias y la resistencia de las ex prisioneras políticas que fueron víctimas de Olderock (Lumi Videla, Beatriz Batazsew, Alejandra Hofstafel entre ellas) en el espacio de la casa y su pasado represivo poniendo de relieve la demanda de las sobrevivientes y colectivos feministas de recuperarla como sitio de memoria de la historia de la lucha política de las mujeres. En este contexto, el pasado es revisado a la luz de las demandas feministas donde la violación sexual se interpreta como una forma de tortura específica contra la mujer militante en la época del terrorismo de estado que se extiende hoy en día a la experiencia de las jóvenes (la amiga íntima de Valentina, quien es otra sobreviviente). También el acoso y asalto sexual se entienden en la obra como formas de violencia contra la mujer en una sociedad fuertemente patriarcal, machista y autoritaria donde los violadores y torturadores quedan impunes. Esta postura está en sintonía con la visión del movimiento feminista chileno en su cuarta ola en cuanto a la violencia contra la mujer y las protestas y marchas que han realizado 3 .

El final de la obra cierra con el grito de lucha de las sobrevivientes al decir "Las mujeres torturadas no nos quedamos calladas," subrayando la importancia de hablar y denunciar el abuso sexual como un asunto político y los pactos de silencio en torno a él. El lema feminista en esta afirmación se da en el principio de hacer del dolor acción política y recuperar la ex casa de tortura para las mujeres.

\section{LOS CRIMINALES Y EL DELITO DE LESA HUMANIDAD}

Como sostiene la psiquiatra Katia Reszczynski, "Olderock mentía cuando recurría al argumento de la amnesia para evitar una pregunta incómoda" (2014: 65). Más aún tendía a hacerse "la loca" cada que vez que le convenía no responder. Por otro lado, usaba "el silencio" y "el comportamiento histriónico" de acuerdo a los temas y épocas que narraba de su vida (Guzmán, 2014: 147).

Los crímenes de Olderock nos horrorizan por su brutalidad y sadismo autorizada por todo un sistema al que sirvió como una eficiente y leal agente. Olderock era una incondicional al terrorismo de estado y a sus superiores. Como muestra Guzmán en las entrevistas, poseía total libertad para aplicar castigos sexuales y torturas brutales. Sus tareas incluían una amplia gama que iban desde el espionaje, los secuestros, la tortura, las desapariciones, los asesinatos hasta la participación en la conocida Operación Cóndor que incluyó toda la región sudamericana. La excapitán era consciente que se podía hacer cualquier cosa en los centros clandestinos y que “todos tenían miedo" dentro y fuera de la DINA (Guzmán, 2014: 111). Más aún explica que "ser de la DINA significaba tener un poder superior a cualquier otra persona de otra institución en Chile," mostrando una evidente seguridad del poder impune del organismo y sus agentes durante

\footnotetext{
${ }^{3}$ La obra se dio en pleno estallido social y político en Santiago en una función gratuita el 29 de noviembre de 2019 en el teatro Antonio Varas con gran presencia de estudiantes secundarios en el público asistente.
} 
la dictadura (Guzmán, 2014: 108). De hecho, el poder que concentraban los altos oficiales que dirigían la DINA era tan grande que los denominaban "La Junta Chica" que funcionaba en base al chantaje, soplonaje y delación. Olderock fue la mujer más cercana a este grupo y la DINA le dio la posibilidad de volcarse a la acción y la disciplina militar que la rutina tediosa de Carabineros le negaba (Guzmán, 2000: 53). Vista hoy, Olderok se revela como una mujer con gran ambición que encontró en la ideología dictatorial y militarista una misión donde canalizó su deseo de reconocimiento y poder.

En el libro de crónicas titulado Los malos (2015) editado por Leila Guerreiro, Manuel Contreras y su subalterna Ingrid Olderock tienen crónicas que toman la forma de "retratos de su perversidad." Sus perfiles aparecen como productos de "nuestra contemporaneidad política" pues, como afirma Guerreiro, no hubieran sido posible sin el contexto dictatorial del Cono Sur. "Detrás de estos malos hay una trama social y política que se sostiene en una estructura de corrupción, sobornos e impunidad". El objetivo del libro Los malos es "humanizar" a estas figuras del terror algo fundamental para comprender el verdadero significado de estas figuras abyectas tuvieron en el pasado y tienen hoy.

\section{MODELO DE TORTURADORA}

Como su padre, Olderock era gran admiradora y experta en el nazismo y, en especial, de Irma Grese, la guardia nazi llamada el "ángel de la muerte," "la perra de Belsen" y "la hiena de Auschwitz", entre otros terribles apelativos relacionados a su violencia. Según los testimonios de sobrevivientes, como Olga Lengyel, era capaz de matar a sangre fría golpeando a las prisioneras en la cabeza o usando sus gruesas y pesadas botas militares para hacerlas tropezar con el fin de que murieran producto del golpe. De acuerdo a los relatos no mostraba ni un rasgo de humanidad ya que su sadismo la había convertido en la "personificación del mal". Por otro lado, sus características sádicas iban de la mano de una gran belleza física, hecho que aparentemente hizo que muchos miembros de la SS se enamoraran de ella y que mantuvieran relaciones. Los prisioneros también notaron esta cualidad y la apodaron "la bella bestia" para referirse a la paradójica y letal combinación de violencia y belleza que la singularizaba entre otras guardias.

Grese pareciera ser el modelo nazi que inspira a Olderock ya que muchas de sus acciones y comportamientos con los y las prisioneros de ambas son muy similares. La frialdad guía su trabajo de torturadora y aplicar los más crueles padecimientos es otro rasgo que las emparenta con una genealogía de mujeres violentas. Grese había sido entrenada como muchos otros miembros de la SS para endurecerse y a acostumbrarse a la brutalidad para realizar su trabajo. Encontramos un paralelo con las enseñanzas que se atribuyen a Olderock en la Escuela de Las Rocas de Santo Domingo en la obra de teatro La mujer de los perros que aparecen en sus recuerdos del primer momento de la dictadura de Pinochet. Por otro lado, vemos también que la orientación sexual y los atributos físicos "anormales" de Olderock forman parte del arquetipo femenino monstruoso que transgrede la moral y la normativa social que afiliado al poder dictatorial se vuelve letal.

La mayoría de las mujeres guardias alemanas, calificadas de sádicas y bestias por ex prisioneros, no eran miembros del partido nazi, sino mujeres comunes y corrientes que habían 
elegido este trabajo por el sueldo, la seguridad y la movilidad social que suponía para personas sin mayores recursos ni estudios. ${ }^{4}$ De modo similar el conocido represor de la DINA, José Avelino Yévenes reveló que ingresó al organismo por razones económicas ya que "su personal tenía mejores condiciones salariales" que otras ramas de las FF.AA y Carabineros. Más aún, tras justificarse por haber trabajado ahí, Yévenes aseguró que nunca "habría tenido casa propia, auto nuevo y una mejor jubilación” a no ser por este puesto (Guzmán, 2000: 17). En este sentido, observamos que la capacidad de ejercer la violencia tiene que ver con una posición al interior de los aparatos represivos y que las motivaciones de trabajar en dichas agencias responden principalmente a deseos de mejora económica y de ascenso social ${ }^{5}$.

En historias y recuentos en primera persona de experiencias traumáticas y terriblemente degradantes, Olderock es identificada por un sadismo despiadado y el uso de animales como parte del sello personal de la tortura sexual que practicaba en el decálogo de horrores de los centros clandestinos. En la mayoría de los textos, obras de teatro y testimonios, Olderock aparece como una suerte de monstruo o sicópata sádica que gozaba con hacer sufrir, física y psíquicamente, y disfrutaba degradando a los prisioneros y prisioneras bajo su cargo ${ }^{6}$. Como afirma la sobreviviente Beatriz Bataszew, mediante la tortura sexual Olderock "buscaba marcar en los cuerpos y en las mentes que eso le pasa a las mujeres y hombres que subvierten el orden establecido" (Guzmán, 2014: 83). Bataszew coincide con los informes clínicos que se hicieron sobre Olderock cuando fue citada por tribunales por las causas de los detenidos desaparecidos de la Venda Sexy mientras aducía no recordar y padecer de amnesia. Los diagnósticos médicos "sostienen que presentaba rasgos sicóticos y una marcada paranoia que probablemente le provocaba delirios” (Matus, 2015: 155).

El sobreviviente Elías Padilla, autor de La Memoria y el Olvido: Detenidos Desaparecidos en Chile, por su parte, afirma que en el centro clandestino la Venda Sexy se realizaba "toda la tarea" de represión, y que los funcionarios eran parte de los operativos, las torturas, los asesinatos y la desaparición de los cuerpos (citado por Guzmán 74-75). ${ }^{7}$ Aquí las prisioneras eran doblemente castigadas por su género y su militancia política. Las denuncias de mujeres militantes que incorpora la dramaturga Patricia Artés a Irán 3730, legitiman sus testimonios sobre el tipo específico y sistemático de tortura que se practicó en la Venda Sexy y que se implementó a manos de la propia Olderock. La agente fustigaba a las prisioneras y a las jóvenes en particular, por quienes mostraba una predilección evidente. Su imagen y fama de depredadora sexual convive en el imaginario de la dictadura con la de brutal torturadora. Los estudios, investigaciones y

\footnotetext{
${ }^{4}$ Crecer con la propaganda nazi desde pequeña y sus instituciones juveniles preparó para el entrenamiento ideológico a las nuevas reclutas alemanas y en pocos días quedaron listas para ejercer la violencia. Muchas no fueron juzgadas y volvieron a sus vidas normales, pero no fue el caso de Irma Grese, quien fue condenada a muerte por crímenes de lesa humanidad (Lauren Willmott en "The Real 'Beast of Belden"? Irma Grese and Female Concentration Camp Guards").

${ }^{5}$ Cabe mencionar que hoy en día los militares tienen las mejores pensiones entre la población chilena como parte del pacto con la democracia.

${ }^{6}$ Esta clase de representación del torturador como un monstruo que se ubica a medio camino entre el animal y el ser humano cobra su mayor y más violenta expresión en el film de terror titulado Trauma (dir. Lucio Rojas, 2017).

7 De los 27 detenidos desaparecidos de este cuartel clandestino, cinco eran mujeres militantes del MIR a quienes Guzmán identifica con nombres y apellidos, edad y filiación política (78).
} 
testimonios afirman esta representación de la agente más cercana a Manuel Contreras, y, por lo tanto, la mujer más poderosa de la DINA. Este poder aparentemente ilimitado, contribuye a la imagen de Olderock como un monstruo que daba rienda suelta a su deseo y voluntad sin rendir cuentas a nadie.

El costo del poder y el miedo que engendraba Olderock se manifiestan en el aislamiento y desprecio con que trabajaba en la DINA, a pesar de estar protegida. Esto se revela en el apodo denigrante que le dieron los demás agentes, llamándola "la chancha," como revela el escritor Jorge Baradit en su Historia secreta de Chile, apodo que la consignaba como sucia, hedionda y repulsiva entre sus pares. El desprecio y la burla de los agentes por Olderock se debía no solo a su mal olor o falta de aseo, sino a su lesbianismo y la llamada "locura" por sus perros como revela Daniel Valdieso. A estos rumores se sumaba el más abyecto de todos y que era voz populi: se decía que practicaba la zoofilia con sus perros, lo que terminó de animalizarla y condenarla al ostracismo. Según un ex fiscal del Ejército entrevistado por Matus, era "una mujer hermética y desconfiada despreciada por sus compañeros quienes rumoreaban historias de zoofilia con sus perros" (205: 156). En la interpretación de Valdieso además de brotes paranoicos y el temor de que la iban a matar después del atentado, mostraba "cuadros depresivos severos" con varios intentos de suicidio. Los suicidios fallidos y que llevaron a Olderock a ser internada en el Hospital de Carabineros con nombre falso también son mencionados en el perfil biográfico de Matus (2015: 156). Uno de estos episodios aparece en la obra teatral La mijer de los perros, donde el delirio sicótico embrutece y distorsiona el mundo y la identidad de Olderock. Debido a sentirse perseguida y al miedo extremo a ser asesinada por agentes de Carabineros, siempre estaba armada e incluso después de la dictadura guardaba una Browning de 9 centímetros en el horno de la cocina y llevaba una pistola en la cartera.

Quien ha sido llamada "la perra rabiosa" y "la monstrua de la DINA", revela cómo operaba el poder al interior de los organismos represivos en el contexto dictatorial y las formas en que torturadoras como ella subvertían su estatus de género subordinado mediante la violencia y el horror que provocaban, ganándose así, el reconocimiento de la institución y sus pares. Utilizando el rostro del terror, Olderock y sus alumnas consiguieron avanzar en una institución organizada en base al secreto y la clandestinidad en una suerte de mafia criminal pensada y dirigida por una cofradía masculina que unió las FFAA y la policía nacional y mantuvo a la población civil amedrentada. Dagoberto Mario Trincado Oliveira recuerda a otra guardia llamada Gabriela Ordenes quien en Villa Grimaldi participaba activamente en las torturas de los prisioneros y era conocida por esto y "porque le gustaban los vejámenes sexuales” (Guzmán, 2014: 81), mostrando que Olderock no era la única ni la excepción.

Olderock descubre en el terror que provoca una forma de dominio sobre el otro, convirtiéndose en un instrumento incondicional del Estado terrorista. El terror funcionó también como la amenaza permanente de casi toda la población, haciendo del inerme su blanco al decir de la filósofa política Adrianna Cavarero (2009: 135). Producto de un régimen de "violencia que se centra en el horror," se reduce a todos los ciudadanos a víctimas potenciales mientras el sistema de vigilancia y los mecanismos ideológicos los obligan a denunciar y a autodenunciarse (2009: 135). El estado aquí arrolla con furia sanguinaria en un movimiento "de purificación que aniquila sus vidas" (2009: 135-136). 
El pacto de "no avanzar el odio" que la oposición política hizo con las FFAA para organizar la transición a la democracia, permitió que ex agentes como Olderock nunca fueran juzgadas. Los relatos de Olderock no revelan la verdad a pesar de los deseos del público. Como argumenta Payne éstas son más bien narrativas que interrumpen el silencio o el deseo de mirar al futuro que los gobiernos democráticos han tenido con respecto al pasado dictatorial no solo en Chile sino en otros países que han vivido violencia política. Los perpetradores tienden a racionalizar y justificar sus acciones y a minimizarlas si no a negar abiertamente cualquier responsabilidad (2008: 2). Las diversas representaciones teatrales, semblanzas e investigaciones sobre Olderock, por otro lado, revelan una serie de interpretaciones sobre la violencia, el sadismo y el dominio del otro por parte de una mujer cuya performance de género no se ajustaba a la heteronormativa. Tanto su género como sexualidad forman un núcleo ideológico que transita en el imaginario chileno y la memoria de la dictadura, por una parte, deshumanizándola como la "perra" y "monstruo" chilena, y, por otra, condenándola no solo por sus acciones criminales como agente del estado torturador sino por un cuerpo y sexualidad fuera de la norma, colapsando lo social y sexual. Para deconstruir la imagen abyecta de la "perra monstruosa" que encarna Olderock, se hace necesario una reflexión que contextualice el lugar y posición de la mujer dentro de los organismos de seguridad. En el escenario dictatorial el género y la sexualidad son esenciales en el funcionamiento de las estructuras de poder que permitieron y garantizaron el dominio, tortura y exterminio de enemigos políticos. La militarización de la mujer y su trabajo dentro de organismos represivos arroja una serie de interrogantes sobre el género y la necesidad de la masculinización como forma de ascender y ser respetada (o temida). Tal como muchos textos muestran en Olderock se unen impunidad y abyección lo que hace extremadamente difícil deslindar el personaje real del mito. Lo que sí es evidente es que adoptó los signos de la masculinidad para conseguir avanzar dentro de las estructuras del poder dictatorial sin importarle nada más. 


\section{BIBLIOGRAFÍA}

BuTLER, Judith (1990). Gender Trouble. Feminism and the Subversion of Identity. New York: Routledge.

Carrera, Ximena (2010). Medusa. Santiago: Biblioteca Nacional.

Cavarero, Adriana (2009). Horrorismo. Nombrando la violencia contemporánea. Barcelona: Anthropos.

Donoso, Claudia, Errázuriz, Paz. "A la vuelta de la esquina; una entrevista con Ingrid Olderock.”. Revista de Crítica Cultural 23 (2001):14-21.

ELTIT, Diamela (2000). Emergencias. Escritos sobre literatura, arte y politica. Santiago: Editorial Planeta.

GuZMÁN, Nancy (2000). Romo: confesiones de un torturador. Santiago: Editorial Planeta.

GuZMán, Nancy (2014). Ingrid Olderock. La mujer de los perros. Santiago: Ceibo.

LAZZARA, Michael (2018). Civil Obedience. Complicity and Complacency in Chile since Pinochet. Wisconsin: The University of Wisconsin Press.

MATUS, Alejandra (2015). “Ingrid Olderock. La entrenadora de perros”. Guerreiro, Leila (ed.). Los malos. Santiago: UDP: 137-159.

PAYNE, Leigh (2008). Unsettling Accounts. Neither Truth Nor Reconciliation in Confessions of State Violence. Durham y Londres: Duke University Press. 